\title{
Application of Novel Processing Methods for Greater Retention of Functional Compounds in Fruit-Based Beverages
}

\author{
Mariana Morales-de la Peña ${ }^{1}$, Jorge Welti-Chanes ${ }^{1}$ and Olga Martín-Belloso ${ }^{1,2, *}$ \\ 1 Tecnológico de Monterrey, Escuela de Ingeniería y Ciencias, Centro de Biotecnología, FEMSA, \\ Av. Eugenio Garza Sada 2501, Monterrey 64849, Mexico; mariana.moralesdlp@itesm.mx (M.M.-d.l.P.), \\ jwelti@itesm.mx (J.W.-C.) \\ 2 Department of Food Technology, University of Lleida, Rovira Roure 191, Lleida 25198, Spain \\ * Correspondence: omartin@tecal.udl.cat; Tel.: +34-973-70-25-93
}

Academic Editor: Tatiana Koutchma

Received: 31 March 2016; Accepted: 30 May 2016; Published: 3 June 2016

\begin{abstract}
Eating habits of western populations are changing due to modern lifestyles. As a result, people are becoming more susceptible to chronic and degenerative diseases. This fact has motivated the food industry to develop functional products that could decrease the incidence of those disorders. It is well known that fruit juices, milk and soymilk possess high concentrations of antioxidant and bioactive substances. Hence, the development of these functional beverages is a potential way to take advantage of their nutritional properties and exotic flavors that could attract the interest of consumers. At the same time, application of the right preservation treatment is of high relevance in order to obtain safe products with convenient shelf life and high concentration of health-related compounds. This fact represents a great challenge that scientists and technologists are currently facing. Today, novel preservation processes such as high hydrostatic pressure (HHP), high intensity pulsed electric fields (HIPEF) and ultrasound (US), among others, are being evaluated as an alternative to heat pasteurization, obtaining promising results. Hence, this review gathers the most relevant information about the development of mixed beverages containing fruit juices and milk or soymilk. Furthermore, the advantages and drawbacks of the application of non-thermal treatments for functional beverages' preservation with high content of bioactive compounds are also mentioned.
\end{abstract}

Keywords: functional beverages; mixed beverages; non-thermal processing; high hydrostatic pressure; high intensity pulsed electric fields; ultrasound; antioxidant properties; bioactive compounds

\section{Introduction}

Current lifestyles of most populations have changed over the past few decades. Usually, lack of time is perceived as the major barrier to practice healthy habits such as exercising and eating natural foods. Based on previous studies, the overall time spent on meal preparation has decreased $38.6 \%$ during the last years [1]. Approximately $64 \%$ and $35 \%$ of men and women, respectively, age 21-64 years reported no time spent in daily food preparation [1,2]. This fact has driven people away from healthy diet patterns and the consumption of "fast food" rich in cholesterol, sugars and fats has increased through the years. As a result, there is a greater incidence of chronic or degenerative disorders such as obesity, stroke, diabetes, certain cancers and osteoporosis, among others, and it is predicted that it will continue growing, causing death in low-, middle- and high-income countries $[1,3]$. Regarding data reported by the World Health Organization (WHO) and the Food and Agriculture Organization (FAO) [4], the proportion of chronic diseases is expected to rise from $46 \%$ to $57 \%$ by 2020 . 
Hence, immediate and effective actions, as well as a rapid change in lifestyle and eating habits, are necessary to demean this current situation.

It is well known that foods are composed of thousands of bioactive substances and antioxidant compounds that exert regulatory activities in human organisms beyond basic nutrition and can have beneficial effects on health [5-7]. A continuous consumption of vitamins, phenolic acids, flavonoids, carotenoids, minerals, amino acids and fatty acids through different foods is highly associated with the reduced risk of chronic and degenerative diseases [8]. In this sense, scientists and technologists have been focused on the development of new easy-to-prepare or ready-to-eat products not only with a high concentration of these compounds, but with attractive sensory characteristics. Among these products, functional beverages are attracting consumers' attention, being perceived as healthy sources of hydration [9]. Pszczola [10] and Sloan [11] reported that the consumption of mixed fruit-based beverages has significantly increased in the last years, becoming one of the food industry sectors with the highest growth worldwide.

Thermal pasteurization is the most used method to obtain safe and shelf-stable beverages; however, the high temperatures achieved during processing usually cause detrimental effects on the desirable antioxidant properties and health related compounds [12]. At present, novel processing technologies such as high hydrostatic pressure (HHP), high intensity pulsed electric fields (HIPEF), ultrasound (US), ultraviolet light (UV), irradiation, and cold plasma, among others, are being applied or explored to process foods at low temperatures, avoiding the negative changes induced by heat. While most of these emerging technologies are being studied, others such as HHP, HIPEF and US have been deeply evaluated and, inclusively, have already being implemented at industrial levels. Through the last few years, different studies have demonstrated that these non-thermal treatments are gentle food preservation techniques capable of inactivating pathogen microorganisms and deteriorative microorganisms and enzymes, providing safe and fresh-like products with minimum changes to their nutritional, physicochemical and sensorial properties [13,14].

The objective of this contribution is to highlight the current developments of functional beverages containing fruit juices and milk or soymilk, and to identify the advantages and drawbacks related to the application of non-thermal treatments for beverage preservation with a higher retention of bioactive compounds.

\section{Current Development of Functional Beverages: Fruit Smoothies and Mixed Beverages Containing Fruit Juices and Milk or Soymilk}

The development and optimization of beverage formulations are very important steps within the beverage innovation process, not only to boost their sensory acceptability, but also their nourishing properties. Fruit juices are great sources of health-related compounds with attractive flavors for all age groups, being perceived as healthy and refreshing products [9]. Hence, a large quantity of fruit-based beverages have appeared on the market during the last decades. According to Hughes [15], fruit-based beverages represent one of the fastest growing areas in the global food industry, and, nowadays, nearly $60 \%$ of adults consume fruit juices.

Usually, commercialized fruit-based beverages contain a $12 \%$ minimum of fruit juice and often have sugar, citric acid and other ingredients [16]. However, since most consumers are currently requesting for minimal-processing products with clean labels, producers are highly motivated to create more natural and fresh-like beverages. In this sense, it has been observed that a mix of two or more fruits can result in beverages, commonly named "smoothies", with an elevated concentration of antioxidant substances, and particular flavor characteristics $[17,18]$. Furthermore, the incorporation of other ingredients such as milk or soymilk provides a considerable concentration of different bioactive compounds that is able to enhance the functional properties of the blend, and, in some cases, improve its physicochemical characteristics, making it more attractive for consumers. 


\subsection{Smoothies}

Basically, the term "smoothie" has been used since the 70s, mainly in North America and United Kingdom; nonetheless, it was not until the 2000s that smoothies re-emerged as a part of the trend towards healthy eating habits. Their preparation is based on the usage of different fruits and/or vegetables which are processed to obtain juice, pulp or puree, and then mixed. They are characterized by an elevated nutrient concentration with low energy content [19]. Furthermore, their consumption supplies nearly the recommended dietary intake of vitamin C (100 mg/day) for adults [20].

Although smoothies' production seems simple, finding the optimal combinations has being a great challenge for scientists and technologists. Through the years, various works have been conducted by different research groups around the globe, using all kinds of fruits from citrus, such as orange and lemon, up to exotic fruits like acerola and passion fruits. Namely, Kumar and Saraswathi [21] performed an experimental design to maximize the sensory acceptability of a beverage containing mango, lemon and orange. Ten formulations were sensorially evaluated, and, as a result, a highly acceptable mixed beverage was prepared by combining orange (33\%), mango $(66 \%)$ and lemon $(1 \%)$. Likewise, a mix of orange juice, which has high vitamin $C$ content, with carrot juice that contains an elevated concentration of $\beta$-carotene, was proposed by Torregrosa et al. [22], obtaining a stable mixed beverage rich in antioxidant compounds. Similarly, De Carvalho et al. [23] blended cashew apple juice with coconut water and observed that the beverage had a high content of vitamin $C$ and elevated levels of minerals such as sodium, potassium, phosphorus, chloride and magnesium coming from the coconut water. Recently, Gironés-Villaplana et al. [24,25] studied the phytochemical composition, antioxidant capacity and bioactive compound stability along the storage of different mixed drinks based on lemon juice and edible berries of exotic origin (maqui, açai, and blackthorn). According to their results, all of the formulated beverages showed high values of antioxidant capacity with strong stability of bioactive compounds during storage, being the lemon-maqui blend that with the highest antioxidant activity. De Sousa et al. [26] prepared a tropical smoothie by mixing different fruits—cashew apple, papaya, guava, acerola fruit and passion fruit-and reported that the beverage was microbiologically stable, with high concentration of vitamin $C$ and great sensorial acceptance, which suggested its potential for commercial distribution. In an interesting study, Jesen et al. [27] studied the beneficial effects of consuming fruit-based beverages in human health. Authors observed that the continuous intake of a blend containing a mixture of fruit juices and berries increased the concentration of antioxidant compounds in the serum blood of consumers; these compounds are able to enter living cells and protect them from oxidative damage. According to Jesen et al. [27], these effects might be attributed to the anthocyanins that mainly come from the berries. Recently, Swada et al. $[28,29]$ reported that combining papaya and strawberry nectars could result in synergistic relationships between their different bioactive compounds such as ascorbic acid and carotenoids, as well as their antioxidant capacity. The authors demonstrated the benefits of blending fruit nectars, producing a superior product with maximum health benefits than either fruit processed individually.

\subsection{Fruit Juice-Milk and Fruit Juice-Soymilk Beverages}

Another successful development in the functional beverage sector is the addition of milk or soymilk to fruit juices to obtain mixed beverages with new sensorial attributes and bioactive compounds coming from milk or soymilk. On one hand, it is well known that milk is considered as the main source of calcium and conjugated linoleic acid in the human diet [30]. Furthermore, it contains a high concentration of proteins and fat soluble vitamins. On the other hand, soy is a rich source of essential amino acids and minerals, such as iron, magnesium and copper, as well as linoleic (omega-6) and alpha-linolenic (omega-3) acids [31-33]. Additionally, soy contains many phenolic compounds and isoflavones that have important biological functions including antioxidant and anticarcinogenic properties [31].

Taking in to account the nutrient profile of milk and soymilk and their numerous health-benefits, both products have been included as main ingredients in new mixed beverages containing one or more 
fruit juices. Furthermore, in the case of soymilk, its beany, bitter, rancid and astringent taste can be masked with the fruit juice flavors. In this sense, fruit juice-milk and fruit juice-soymilk beverages are being well perceived by consumers, and they are becoming very popular in American and European markets at present [8]. As a result of the high success of these products, scientists and technologists are trying to innovate and find the best combinations in terms of bioactive compound content and flavor. At the same time, the maintenance of biological activity and physical properties stability (e.g., solubility) during processing and throughout the shelf -life of the final product are important aspects to be considered when blending these foodstuffs.

Today, different commercial beverages, based on blends of fruit juices and whole milk, skim milk or soymilk exist in the market. Zulueta et al. [8] conducted a complete study evaluating the nutritional aspects of 17 fruit juice-milk beverages commercialized in Spain. Authors observed that the beverages contained approximately between $7 \%$ and $43 \%$ of different fruit juices and $3 \%-20 \%$ of milk or skim milk. The main contribution to the total antioxidant capacity of the beverages was provided by the vitamin $C$ content, followed by phenolic compounds. Furthermore, they reported that, depending on the fruits used as raw material, each beverage possessed different contents of vitamin $\mathrm{C}$ and, consequently, different antioxidant capacity. Authors stated that lemon and orange were the fruits that provided the highest concentrations of vitamin C. Similarly, the isoflavone content and antioxidant capacity of different commercial soy beverages blended with fruit juices were evaluated by Rostagno et al. [34] and Rau de Almedia et al. [35]. Authors agreed that there was a wide variation in the isoflavone concentration and antioxidant capacity among products, which mainly resulted from the different ingredients used in the beverages and the type of preservation process applied.

Regarding mixed beverages with whole or skim milk, Zulueta [36] developed an orange juice-skim milk beverage as an alternative to traditional soft drinks. As reported by the authors, the final product containing $50 \%$ of pasteurized orange juice and $20 \%$ of ultra-pasteurized skim milk was an excellent source of vitamin C, vitamin A, phenolic compounds and fatty acids. Likewise, Salvia-Trujillo et al. [37] observed that a mixed beverage containing a blend of orange, kiwi, pineapple and mango juices $(75 \%)$ combined with whole or skim milk (17.5\%) possessed high antioxidant capacity which was well-related with its content of vitamin C. In a different study, Afifi et al. [38] evaluated the physicochemical changes during the processing of a spray-dried mixed beverage containing a blend of concentrated fruit juices (grape and peach-23\%) and fresh or pasteurized whole milk (73\%). The authors concluded that the presence of sugar, fat and protein components in a complex system may play an important role in the physical and chemical stability of such products. Furthermore, the beverage was found to be rich in health-related compounds, such as vitamin A, C, riboflavin, $\beta$-carotene, polyphenols, calcium, phosphorus, magnesium, and potassium. In addition, different studies carried out during the last decade agree that the addition of different fruit juices to soymilk helps to mask its beany flavor, resulting in greater consumer acceptance [33,39-41] and, at the same time, improves the nutritional and therapeutic value of the final product [35,41]. Potter et al. [40] developed a blueberry-soy blend with $12 \%$ of blueberry juice and $2.8 \%$ of soy protein isolate. Their results demonstrated that the beverage was stable and with an important amount of anthocyanins. Similarly, a mixed beverage containing $50 \%$ of a fruit juice blend (orange, pineapple and kiwi juices) and $42.5 \%$ of pasteurized soymilk represented a great source of vitamin C, phenolic compounds and isoflavones, with high antioxidant capacity [42,43].

Overall, the fact of mixing fruit juices with milk or soymilk can effectively improve their nutritional value. Furthermore, by selecting the appropriate ingredients in the right proportions it may be possible to produce a final product with healthy attributes and adequate sensory characteristics. Nonetheless, despite the large number of mixed beverages currently available in the market, there is still a great challenge to develop new products rich in antioxidant and bioactive compounds that meet consumer requirements while dealing with modern lifestyles. In this way, the application of adequate preservation technologies is needed to prolong their shelf life without compromising their nutritional, sensory and fresh-like characteristics, while avoiding the use of chemical preservatives. Today, 
thermal pasteurization is the most common treatment applied for functional beverage preservation; nevertheless, the high temperatures achieved during processing usually produce detrimental effects on their nutritive constituents. Therefore, non-thermal technologies have been studied during the last decades as an alternative to conventional treatments in order to obtain safe products with an elevated functional potential.

\section{Application of Non-Thermal Technologies in Fruit-Based Beverages}

Thermal treatments, such as pasteurization and sterilization, are the processes commonly applied by the food industry for functional beverage preservation because of their ability to kill microorganisms and inactivate enzymes. On the one hand, sterilization implies the application of high temperature $\left(135-150{ }^{\circ} \mathrm{C}\right)$ for short periods of time between 4 and $15 \mathrm{~s}$ [44] to obtain safe products with extended shelf life ( $>2$ years), which could be stored at ambient temperature. Pasteurization is defined as "mild heat treatment," which implies the application of temperatures between 90 and $99{ }^{\circ} \mathrm{C}$ for $15-30 \mathrm{~s}$ [45]. Usually, this treatment better maintains product quality better than sterilization, but refrigeration storage is required.

Diverse studies have demonstrated, however, that the high temperatures achieved during both processes, sterilization and pasteurization, often lead to chemical and physical changes that affect sensorial properties and reduce the content or bioavailability of some nutrients [46-50]. This fact represents a remarkable disadvantage for the food industry and is currently promoting the application of novel technologies not only to obtain high-quality foods with fresh-like characteristics, but also products with improved or even more novel functionalities [51].

According to Morales-de la Peña et al. [52], and Lado and Yousef [53], non-thermal processes such as HHP, HIPEF, US, pulsed light, irradiation, oscillating magnetic fields and low temperature-plasma have been under development during the last decades and are considered to be more efficient to preserve better quality attributes in food products than heat treatments. Nevertheless, while some of them are still at a basic level of investigation, the application of HHP, HIPEF and US for food processing and preservation has become of considerable interest in food research and development; inclusively, HHP and HIPEF are currently used at a commercial level for beverage preservation.

In general, these emerging technologies are applied at ambient or moderate temperatures in order to eliminate pathogenic/spoilage microorganisms. Some of these techniques are inherently batch processes, while others are adaptable to continuous flow applications. Additionally, they are locally clean processes, and, therefore, appear to be more environmentally friendly than the traditional ones [54]. HHP is considered a non-thermal and additive-free processing in which products can be treated up to $600 \mathrm{MPa}$. According to Oey et al. [55], different microorganisms and some enzymes can be inactivated by HHP with minimal effects on product quality and sensory properties. Due to its limited effect on the covalent bonds of low molecular mass compounds, such as vitamins and other phytochemicals, HHP-treated beverages have similar or even enhanced nutritional values than fresh products [56]. On the other hand, HIPEF processing is considered a feasible alternative or complementary process to heat pasteurization in the field of liquid foods such as functional beverages. Basically, when high electric fields $(>20 \mathrm{kV} / \mathrm{cm})$ are applied in pulse form to liquid products for short periods of time, several microorganisms and deteriorative enzymes are inactivated, with the advantage of retaining, or minimally modifying, sensorial, physicochemical, and health-promoting attributes of the final products $[57,58]$. Likewise, US processing itself or in combination with heat and/or pressure is an effective treatment for microbial inactivation and phytochemical retention [59]. Fundamentally, US refers to the application of sound waves beyond the audible frequency range ( $>20 \mathrm{kHz}$ ). When US is transmitted in a liquid medium, its interaction with the liquid and dissolved gas leads to an exciting phenomenon known as acoustic cavitation [60]. By the regulation of power dissipation, treatment time, duty cycle, and temperature of the US treatment, the cavitation phenomena can maximize the microbial inactivation, diminishing the effects on quality and functional attributes of the treated products [46,60-62]. 
Since most of the studies conducted with HHP, HIPEF and US have confirmed that these techniques are able to inactivate microorganisms and deteriorative enzymes at different levels to obtain safe and stable products, researchers are inquiring into the evaluation of the effects today of non-thermal treatments on nutraceutical compounds and antioxidant properties of different foods such as fruit juices, milk, soymilk and mixed beverages [13,37,42,43,56,63-68]. Most of these studies have been focused on the effects of HHP and HIPEF, while the application of US in these kinds of products is still at the basic level.

Among the health-related substances present in mixed beverages, vitamin $C$, phenolic compounds and carotenoids have been the most analyzed. Vitamin $C$ is a thermolabile compound; thus, has been used as a key indicator for the retention of other vitamins during processing. Barba et al. [56] evaluated the ascorbic acid concentration of a vegetable beverage containing tomato, green pepper, celery, onion, carrot, lemon and olive oil treated with $\operatorname{HHP}(100,200,300$ and $400 \mathrm{MPa}$ from 120 to $540 \mu \mathrm{s})$ and thermal pasteurization $\left(90-98^{\circ} \mathrm{C}\right.$ for 15 and $\left.21 \mathrm{~s}\right)$. Obtained results indicated that ascorbic acid was better preserved by HHP than by thermal treatment. In two different studies, Carbonell-Capella et al. [64] and Barba et al. [69] developed a fruit smoothie and an orange juice-milk beverage, respectively, which were treated with HHP at different conditions of 300-500 MPa for 5-15 min [69] and 100-400 MPa for 3, 5, 7 and 9 min [65]. Both research groups agreed that, immediately after HHP, the retention of ascorbic acid in both beverages was higher than $90 \%$, regardless of the treatment applied. These data are well related with previous works in which the ascorbic acid concentration of fruit and vegetable juices was minimally affected by HHP at mild temperatures [70]. Similarly, HIPEF processing has been applied in different mixed beverages such as gazpacho, which is a cold vegetable soup containing tomato, cucumber, green pepper, onion, garlic and olive oil, with the aim to evaluate the vitamin $C$ retention in the samples immediately after treatment [13]. In this study, the authors concluded that pulses in bipolar mode and lower electric field strength, treatment time, pulse frequency and width led to a product with a higher concentration of vitamin C (84.5\%-97.1\%). Likewise, Zulueta et al. [71], Salvia-Trujillo et al. [37], and Morales-de la Peña et al. [42] reported that HIPEF treated orange juice-milk, fruit juice-milk and fruit juice-soymilk beverages, respectively, at different processing conditions, had a higher retention of vitamin $\mathrm{C}$ compared to the heat processed ones. In a recent study, Carbonell-Capella et al. [72] compared the effects of HIPEF and US processing on ascorbic acid of a fruit juice blend (mango and papaya) sweetened with Stevia rebaudiana. They observed that US was the processing technique that better retained the ascorbic acid content of the beverage $(84 \%-91 \%)$, followed by HIPEF ( $80 \%-83 \%)$. Authors reported that, in any case, higher energy inputs caused higher ascorbic acid losses, independently of the treatment applied, which may be caused by the increase in the temperature at high energy levels.

Phenolic compounds are commonly present in fruits and vegetables. The beneficial health-related effects of certain polyphenols or their potential antioxidant properties are of great importance to consumers [73-75]. Hence, their retention in treated functional beverages is an important goal for scientists and technologists. Barba et al. [56] reported that, after an HHP treatment (100 MPa/420 s) was applied to an orange juice-milk beverage, its content of phenolic compounds significantly increased $(22 \%)$ in comparison with untreated samples. This effect may be related to a better extractability of some of the antioxidant components following HHP processing. Conversely, Keenan et al. [76] reported that HHP (400 MPa/5 min) significantly reduced the phenolic content of a fruit smoothie. However, when these authors compared the amount of phenolic compounds in HHP and thermally treated smoothies, those samples treated with HHP retained a higher concentration of these compounds. Morales-de la Peña et al. [42] observed that there were no significant differences in total phenolic concentration between untreated, HIPEF and thermally treated fruit juice-soymilk beverages immediately after processing. Nonetheless, during the storage, thermally treated beverages showed a significant decrease in the phenolic content after the third day, while those HIPEF processed remained with no significant changes. Conversely, when US treatment was applied in a fruit smoothie at different amplitude levels $(24.4-61 \mu \mathrm{m})$ and processing times (3-10 $\mathrm{min})$, it was observed that the total phenolic content 
decreased with the increase of amplitude levels [68]. These degradation trends during US processing may be related to the formation of free radicals that occur during sonication, resulting in a potential development of different oxidation pathways [77]. When Carbonell-Capella et al. [72] compared the effects of HIPEF and US processing on phenolic compounds of a mango-papaya blended beverage, they reported that the concentration of these compounds after HIPEF processing was significantly higher than those of untreated samples. Authors stated that the extractability of total phenolic compounds may be increased by the release of the solutes into the solvent due to the irreversible pores in cell membranes formed by the effects of the electrical fields. However, when the US treatment was applied, insignificant differences were obtained when compared with untreated blended beverage, independently of the energy input applied.

Carotenoids are considered potent antioxidants, due to their pro-vitamin A activity and being free radical scavengers [78]. In addition, it has been reported that they modulate the pathogenesis of cancers and coronary hearth diseases $[79,80]$. Hence, producers and scientists are interested in finding technologies able to preserve their concentration as high as possible in functional beverages. In this sense, a study conducted by Barba et al. [73] demonstrated that there was a statistical significant increase $(35 \%-47 \%)$ in total carotenoid content in orange juice-milk samples after different HHP (100-400 MPa) for 420 and $540 \mathrm{~s}$ in comparison with control samples. According to Butz et al. [81], this increase may be due to the breakage of the intracellular vacuoles and the cell walls of the plant when pressures of $100 \mathrm{MPa}$ are applied. Similarly, HIPEF processing (25, 30, 35 and $40 \mathrm{kV} / \mathrm{cm}$ from 30 to $340 \mu \mathrm{s})$ applied to an orange-carrot mixed juice caused a significant increase in the concentration of different carotenoids [63]. These authors reported an enhancement of carotenoid concentration by increasing the treatment time. Likewise, Carbonell-Capella et al. [72] observed that after HIPEF processing was applied in a papaya-mango blended beverage, the total carotenoid content was significantly higher than in the untreated sample. This may be due to carotenoids being released or leaching from other minerals or solid substances into the juices as a result of the pulsed electric fields [82]. However, different observations were reported by Morales-de la Peña et al. [83] who mentioned that the concentration of total carotenoids in fruit juice-soymilk beverages was significantly diminished (9.8\%-18.4\%) immediately after HIPEF processing at $35 \mathrm{kV} / \mathrm{cm}$ during 800 and $1400 \mu \mathrm{s}$. Nonetheless, these losses were lower than those observed after thermal pasteurization (25.9\%). Regarding US treatment, it has been detected that carotenoid content in a papaya-mango blended beverage after sonication was significantly enhanced compared to the fresh beverage [72]. Differently from other technologies, higher treatment time of US led to a higher carotenoid content. A possible explanation for this increase may be related to the ability of US to enhance disruption of cell walls, which might have facilitated the release of bound carotenoid content, or the rupture of carotenoid-protein binding, thus facilitating the extractability of carotenoids.

Overall, all the studies mentioned above elucidate the great advantages of HHP, HIPEF and US as novel additive-free preservation technologies for functional beverages. Firstly, it has been proved that these processes can produce safe and stable beverages. Secondly, in most of the cases, the main bioactive compounds present in these products are well retained or inclusive their concentration increases. However, as it has been noted, the underlying principles and mechanisms that govern these changes are not yet fully understood; therefore, further investigation is still needed in order to define if biochemical, enzymatic or microbiological reactions might occur during processing, causing the retention, degradation or formation of health-related compounds in the final products. Furthermore, it is of high importance to highlight that the effects of each technology over bioactive compounds retention in treated beverages depend on different factors: (i) processing parameters; (ii) processing equipment; (iii) food matrices and; (iv) fruit ripeness and variety. In order to apply the optimal treatment and obtain functional beverages with an elevated concentration of health-related compounds, all of these factors should be considered depending on the selected technology. This information could open the doors for non-thermal technologies' applications in the food industry. In addition, studies 
focused on bioaccessibility and bioavailability are required to prove if the bioactive compounds present in treated fruit-based beverages can be well absorbed by the organisms, producing health benefits.

\section{Conclusions}

Functional beverages containing a blend of fruit juices, milk or soymilk, have been developed during the last few years in order to meet current consumer demands and provide them with an easy way of ingesting healthy foods. These products could be considered as excellent sources of nutrients and functional compounds to provide wellness and decrease the risk of chronic and degenerative diseases. Nonetheless, food manufacturers must seek to identify the optimal combination of ingredients in order to offer products with a high content of bioactive compounds, antioxidant capacity, and sensorial attributes of high quality. At the same time, food safety has to be achieved through preservation methods, making shelf life stable. Hence, novel technologies have been developed with great success. Today, these treatments are of specific interest to the food industry because they not only provide attractive alternatives to conventional methods such as sterilization and pasteurization, but also offer opportunities for obtaining nourishing beverages. Today, research into functional beverages should be directed towards: (i) identification of food ingredients with high content of antioxidant and bioactive compounds; (ii) developing technologies to ensure commercially stable products; (iii) assessing the effects of new processes on the products compared with traditional treatments; and (iv) demonstrating their efficacy in reducing the risk of chronic and degenerative diseases. Finally, in order to increase product acceptance among consumers, it is of high importance to provide comprehensive information related to the health benefits of these new foods.

Acknowledgments: Mariana Morales-de la Peña thanks the Tecnológico de Monterrey (México) for the postdoctoral Research Funds.

Conflicts of Interest: The authors declare no conflict of interest.

\section{Abbreviations}

The following abbreviations are used in this manuscript:

$\begin{array}{ll}\text { HPP } & \text { high hydrostatic pressure } \\ \text { HIPEF } & \text { high intensity pulsed electric fields } \\ \text { US } & \text { Ultrasound } \\ \text { TCC } & \text { total carotenoid content }\end{array}$

\section{References}

1. Jabs, J.; Devine, C.M. Time scarcity and food choices: An overview. Appetite 2006, 47, 196-204. [CrossRef] [PubMed]

2. Sayer, L.C. Time Use, Gender and Inequality: Differences in Men's and Women's Market, Nonmarket, and Leisure Time. Ph.D. Thesis, University of Maryland, Colege Park, MD, USA, 2001.

3. Granato, D.; Branco, G.F.; Cruz, A.G.; Faria, J.D.A.F.; Shah, N.P. Probiotic dairy products as functional foods. Compr. Rev. Food Sci. Food Saf. 2010, 9, 455-470. [CrossRef]

4. WHO/FAO. Diet, Nutrition and the Prevention of Chronic Diseases: Report of a Joint WHO/FAO; WHO/FAO: Geneva, Switzerland, 2004.

5. Prado, F.C.; Parada, J.L.; Pandey, A.; Soccol, C.R. Trends in non-dairy probiotic beverages. Food Res. Int. 2008, 41, 111-123. [CrossRef]

6. Meisel, H. Bioactive peptides from milk proteins: A perspective for consumers and producers. Aust. J. Dairy Technol. 2001, 56, 83-91.

7. Minervini, F.; Algaron, F.; Rizzello, C.G.; Fox, P.F.; Monet Vand Gobbetti, M. Angiotensin I-converting enzyme inhibitory and antibacterial peptides from Lactobacillus helveticus PR4 proteinase hydrolyzed caseins of milk from six species. Appl. Environ. Microbiol. 2003, 69, 5297-5305. [CrossRef] [PubMed] 
8. Zulueta, A.; Esteve, M.J.; Frasquet, I.; Frígola, A. Vitamin C, vitamin A, phenolic compounds and total antioxidant capacity of new fruit juice and skim milk mixture beverages marketed in Spain. Food Chem. 2007, $103,1365-1374$.

9. Tuorila, H.; Cardello, A.V. Consumer response to an off-flavour in juice in the presence of specific health claims. Food Qual. Preference 2002, 13, 561-569. [CrossRef]

10. Pzczola, D. Making fortification functional. Food Technol. 2005, 59, 44-61.

11. Sloan, A.E. Top 10 global food trends. Food Technol. 2005, 59, 20-32.

12. Plaza, L.; Sánchez-Moreno, C.; Elez-Martínez, P.; de Ancos, B.; Martín-Belloso, O.; Cano, M.P. Effect of refrigerated storage on vitamin $C$ and antioxidant activity of orange juice processes by high-pressure or pulsed electric fields with regard to low pasteurization. Eur. Food Res. Technol. 2006, 223, 487-493. [CrossRef]

13. Elez-Martínez, P.; Martín-Belloso, O. Effects of high intensity pulsed electric field processing conditions on vitamin $C$ and antioxidant capacity of orange juice and gazpacho, a cold vegetable soup. Food Chem. 2007, 102, 201-209. [CrossRef]

14. Soliva-Fortuny, R.; Balasa, A.; Knorr, D.; Martín-Belloso, O. Effects of pulsed electric fields on bioactive compounds in foods: A review. Trends Food Sci. Technol. 2009, 20, 544-556. [CrossRef]

15. Hughes, K. Functional foods. Back to the future. Prep. Foods 2001, 170, 35-36.

16. European Commission. Regulation (EC) No. 1333/2008 of the European Parliament and of the Council of 16 December 2008 on food additives. Off. J. Eur. Union 2008, L354, 16.

17. Akinwal, T.O. Cashew apple juice: Its use in fortifiying the nutritional quality of some tropical fruits. Eur. Food Res. Technol. 2000, 211, 205-207. [CrossRef]

18. Jain, S.K.; Khurdiya, D.S. Vitamin C enrichment of fruit juice based ready-to-serve beverages through blending of Indian gooseberry (Emblica officinalis Gaertn) juice. Plant Food Hum. Nutr. 2004, 59, 63-66. [CrossRef]

19. Watzl, B. Smoothies-Wellness aus der Flasche? Ernährungsumschau 2008, 6, 352-353.

20. Müller, L.; Gnoyke, S.; Popken, A.M.; Böhm, V. Antioxidant capacity and related parameters of different fruit formulations. LWT Food Sci. Technol. 2010, 43, 992-999. [CrossRef]

21. Kumar, S.B.; Ravi, R.; Saraswathi, G. Optimization of Fruit Punch Using Mixture Design. J. Food Sci. 2010, 75, S1-S7. [CrossRef] [PubMed]

22. Torregrosa, F.; Esteve, M.J.; Frígola, A.; Cortés, S. Ascorbic acid stability during refrigerated storage of orange-carrot juice treated by high pulsed electric field and comparison with pasteurized juice. J. Food Eng. 2006, 73, 339-345. [CrossRef]

23. De Carvalho, J.M.; Maia, G.A.; de Figueiredo, R.W.; de Brito, E.S.; Rodrigues, S. Development of a blended nonalcoholic beverage composed of coconut water and cashew apple juice containing caffeine. J. Food Qual. 2007, 30, 664-681. [CrossRef]

24. Gironés-Villaplana, A.; Mena, P.; García-Viguera, C.; Moreno, D.A. A novel beverage rich in antioxidant phenolics: Maqui berry (Aristotelia chilensis) and lemon juice. LWT Food Sci. Technol. 2012, 47, 279-286. [CrossRef]

25. Gironés-Villaplana, A.; Valentão, P.; Moreno, D.A.; Ferreres, F.; García-Viguera, C.; Andrade, P.B. New beverages of lemon juice enriched with exotic berries Maqui, Açai, and Blackthorn: Bioactive components and in vitro biological properties. J. Agric. Food Chem. 2012, 60, 6571-6580. [CrossRef] [PubMed]

26. De Sousa, P.H.M.; Maia, G.A.; de Azeredo, H.M.C.; Ramos, A.M.; de Figueiredo, R.W. Storage stability of a tropical fruit (cashew apple, acerola, papaya, guava and passion fruit) mixed nectar added caffeine. Int. J. Food Sci. Technol. 2010, 45, 2162-2166. [CrossRef]

27. Jensen, G.S.; Wu, X.; Patterson, K.M.; Barnes, J.; Carter, S.G.; Scherwitz, L.; Beaman, R.; Endres, J.R.; Schauss, A.G. In vitro and in vivo antioxidant and anti-inflammatory capacities of an antioxidant-rich fruit and berry juice blend. Results of a pilot and randomized, double-blinded, placebo-controlled, crossover study. J. Agric. Food Chem. 2008, 56, 8326-8333. [CrossRef] [PubMed]

28. Swada, J.G.; Keeley, C.J.; Mohammad, A.G.; Engeseth, N.J. Synergistic potential of papaya and strawberry nectar blends focused on specific nutrients and antioxidants using alternative thermal and non-thermal processing techniques. Food Chem. 2016, 199, 87-95. [CrossRef] [PubMed]

29. Swada, J.G.; Keeley, C.J.; Mohammad, A.G.; Engeseth, N.J. Relationship between pulp structure breakdown and nutritional value of papaya (Carica papaya) and strawberry (Fragaria $\mathrm{x}$ ananassa) nectars using alternative thermal and non-thermal processing techniques. J. Food Sci. Agric. 2015, 96, 2514-2523. [CrossRef] [PubMed] 
30. Givens, D.I.; Kliem, K.E. Improving the nutritional quality of milk. In Functional and Speciality Beverage Technology; Paquin, P., Ed.; CRC Press: Boca Raton, FL, USA, 2009; pp. 135-169.

31. Amigo-Benavent, M.; Silván, J.M.; Moreno, F.J.; Villamiel, M.; del Castillo, M.D. Protein quality, antigenicity, and antioxidant activity of soy-based foodstuffs. J. Agric. Food Chem. 2008, 56, 6498-6505. [CrossRef] [PubMed]

32. Paulsen, P.V. Isolated soy protein usage in beverages. In Functional and Speciality Beverage Technology; Paquin, P., Ed.; CRC Press: Boca Raton, FL, USA, 2009; pp. 318-345.

33. Oliveira, M.A.; Moura, M.; Godoy, R.; Nele, M.; Delizia, R.; Vendramini, A.L. Development of an acai-soymilk beverage: Characterization and consumer acceptance. Braz. J. Food Technol. 2010, 13, 306-312. [CrossRef]

34. Rostagno, M.A.; Palma, M.; Barroso, C.G. Ultrasound-assisted extraction of isoflavones from soy beverages blended with fruit juices. Anal. Chem. Acta 2007, 597, 265-272. [CrossRef] [PubMed]

35. Rau De Almeida Callou, K.; Sadigov, S.; Lajolo, F.M.; Genovese, M.I. Isoflavones and antioxidant capacity of commercial soy-based beverages: Effect of storage. J. Agric. Food Chem. 2010, 58, 4284-4291. [CrossRef] [PubMed]

36. Zulueta, A. Changes in Bioactive and Antioxidant Compounds of a Juice-Soymilk Beverage Treated by Nonthermal Technologies. Ph.D. Thesis, University of Valencia, Valencia, Spain, 2009.

37. Salvia-Trujillo, L.; Morales-de la Peña, M.; Rojas-Graü, M.A.; Martín-Belloso, O. Changes in water-soluble vitamins and antioxidant capacity of fruit juice-milk beverages as affected by high-intensity pulsed electric fields (HIPEF) or heat during chilled storage. J. Agric. Food Chem. 2011, 59, 10034-10043. [CrossRef] [PubMed]

38. Afifi, H.S.; Abu Shelaibi, A.A.; Laleye, L.C.; Ismail, I.A. Measurement of thermal characteristics of spray-dried milk and juice blend. Int. J. Food Sci. Nutr. 2009, 60, 89-98. [CrossRef] [PubMed]

39. Valim, M.F.; Rossi, E.A.; Silva, R.S.F.; Borsato, D. Sensory Acceptance of a Functional Beverage Based on Orange Juice and Soymilk. Braz. J. Food Technol. 2003, 6, 153-156.

40. Potter, R.M.; Dougherty, M.P.; Halteman, W.A.; Camire, M.E. Characteristics of wild blueberry-soy beverages. LWT Food Sci. Technol. 2007, 40, 807-814. [CrossRef]

41. Sakhale, B.; Pawar, V.N.; Ranveer, R.C. Studies on development of soymilk based mango RTS beverage. Electron. J. Environ. Agric. Food Chem. 2012, 11, 523-528.

42. Morales-de la Peña, M.; Salvia-Trujillo, L.; Rojas-Graü, M.A.; Martín-Belloso, O. Impact of high intensity pulsed electric field on antioxidant properties and quality parameters of a fruit juice-soymilk beverage in chilled storage. LWT Food Sci. Technol. 2010, 43, 872-881. [CrossRef]

43. Morales-de la Peña, M.; Salvia-Trujillo, L.; Rojas-Graü, M.A.; Martín-Belloso, O. Isoflavone profile of a high intensity pulsed electric field or thermally treated fruit juice-soymilk beverage stored under refrigeration. Innov. Food Sci. Emerg. Technol. 2010, 11, 604-610. [CrossRef]

44. Bello, J. Ciencia Bromatológica: Principios Generales de los Alimentos; Diaz de Santos, S.A.: A Coruña, Spain, 2000.

45. Braddock, R.J. Single strength orange juices and concentrate. In Handbook of Citrus by-Products and Processing Technology; Wiley, J., Ed.; Wiley: New York, NY, USA, 1999; pp. 53-83.

46. Soria, A.C.; Villamiel, M. Effect of Ultrasound on the technological properties and bioactive of food: A review. Trends Food Sci. Technol. 2010, 21, 323-331. [CrossRef]

47. Rodrigo, D.; Zuñiga, M.; Rivas, A.; Martı́nez, A.; Notermans, S. Microbiological aspects: Adaptation potential. In Food Preservation by Pulsed Electric Fields: From Research to Application; Notermans, S., de Haan, S.W.H., Lelieveld, H.L.M., Eds.; Woodhead Publishing: Cambridge, UK, 2007.

48. Odriozola-Serrano, I.; Soliva-Fortuny, R.; Martín-Belloso, O. Changes on health related compounds throughout cold storage of tomato juice stabilized by thermal or high intenisty pulsed electric field treatments. Innov. Food Sci. Emerg. Technol. 2008, 9, 272-279. [CrossRef]

49. Elez-Martínez, P.; Aguiló-Aguayo, I.; Martín-Belloso, O. Inactivation of orange juice peroxidase by high-intensity pulsed electric fields as influenced by processing parameters. J. Food Sci. Agric. 2006, 86, 71-81. [CrossRef]

50. Sánchez-Moreno, C.; Cano, M.P.; de Ancos, B.; Plaza, L.; Olmedilla, B.; Granado, F.; Elez-Martínez, P.; Martín-Belloso, O.; Martín, A. Intake of Mediterranean vegetable soup treated by pulsed electric fields plasma vitamin C and antioxidant biomarkers in humans. Int. J. Food Sci. Nutr. 2005, 56, 115-124. [CrossRef] [PubMed] 
51. Ashokkumar, M.; Sunartio, D.; Kentish, S.; Mawson, R.; Simons, L.; Vilkhu, K.; Versteeg, C. Modification of food ingredients by ultrasound to improve functionality: A preliminary study on a model system. Innov. Food Sci. Emerg. Technol. 2008, 9, 155-160. [CrossRef]

52. Morales-de la Peña, M.; Salvia-Trujillo, L.; Martín-Belloso, O. Processing the Latest Developments. In Food \& Beverage International; December; 2010; pp. 16-19.

53. Lado, B.; Yousef, A.E. Alternative food-preservation technologies: Efficacy and mechanisms. Microbes Infect. 2002, 4, 433-440. [CrossRef]

54. Señorans, F.J.; Ibáñez, E.; Cifuentes, A. New Trends in Food Processing. Crit. Rev. Food Sci. Nutr. 2003, 43, 507-526. [CrossRef] [PubMed]

55. Oey, I.; Plancken, I.V.; Loey, A.V.; Hendrickx, M. Does high pressure processing influence nutritional aspects of plant based food systems? Trends Food Sci. Technol. 2008, 19, 300-308. [CrossRef]

56. Barba, F.J.; Esteve, M.J.; Frigola, A. Ascorbic acid is the only bioactive that is better preserved by high hydrostatic pressure than by thermal treatment of vegetable beverages. J. Agric. Food Chem. 2010, 58, 10070-10075. [CrossRef] [PubMed]

57. Sánchez-Vega, R.; Elez-Martínez, P.; Martín-Belloso, O. Influence of high intensity pulsed electric field processing parameters on antioxidant compound of broccoli juice. Innov. Food Sci. Emerg. Technol. 2014, 29, 170-177. [CrossRef]

58. Odriozola-Serrano, I.; Aguiló-Aguayo, I.; Soliva-Fortuny, R.; Martín-Belloso, O. Pulsed electric fields processing effects on quality and health-related constituents of plant-based foods. Trends Food Sci. Technol. 2013, 29, 98-107. [CrossRef]

59. Rawson, A.; Patras, A.; Tiwari, B.K.; Noci, F.; Koutchma, T.; Brunton, N. Effect of thermal and non-thermal processing technologies on the bioactive content of exotic fruits and their products: Review of recent advances. Food Res. Int. 2011, 44, 1875-1887. [CrossRef]

60. Chandrapala, J.; Oliover, C.; Kentish, S.; Ashokkumar, M. Ultrasonic in food processing. Ultrason. Sonochem. 2012, 19, 975-983. [CrossRef] [PubMed]

61. Chemat, F.; Zill-e-Huma; Khan, M.K. Applications of ultrasound in food technology: Processing, preservation and extraction. Ultrason. Sonochem. 2011, 18, 813-835. [CrossRef] [PubMed]

62. Cárcel, J.A.; García-Pérez, J.V.; Benedito, J.; Mulet, A. Food process innovation through new technologies: Use of ultrasound. J. Food Eng. 2012, 110, 200-207. [CrossRef]

63. Torregrosa, F.; Cortés, C.; Esteve, M.J.; Frigola, A. Effects of high intensity pulsed electric fields processing and conventional heat treatment on orange-carrot juice carotenoids. J. Agric. Food Chem. 2005, 53, 9619-9525. [CrossRef] [PubMed]

64. Carbonell-Capella, J.M.; Barba, F.J.; Esteve, M.J.; Frígola, A. High pressure processing of fruit juice mixture sweetened with Stevia rebaudiana Bertoni: Optimal retention of physical and nutritional quality. Innov. Food Sci. Emerg. Technol. 2013, 18, 48-56. [CrossRef]

65. Gómez-López, V.M.; Orsoliana, L.; Martínez-Yépeza, A.; Tapia, M.S. Microbiological and sensory quality of sonicated calcium-added orange juice. LWT Food Sci. Technol. 2010, 43, 808-813. [CrossRef]

66. Rivas, A.; Rodrigo, D.; Martínez, A.; Barbosa-Cánovas, G.V.; Rodrigo, M. Effect of PEF and heat pasteurization on the physical-chemical characteristics of blended orange carrot juice. LWT Food Sci. Technol. 2006, 39, 1163-1170. [CrossRef]

67. Walkling-Ribeiro, M.; Noci, F.; Cronin, D.A.; Lyng, J.G.; Morgan, D.J. Shelf life and sensory attributes of a fruit smoothie-type beverage processed with moderate heat and pulsed electric fields. LWT Food Sci. Technol. 2010, 43, 1067-1073. [CrossRef]

68. Keenan, D.F.; Tiwari, B.K.; Patras, A.; Gormley, R.; Butler, F.; Brunton, N.P. Effect of sonication on the bioactive, quality and rheological characteristics of fruit smoothies. Food Sci. Technol. 2012, 47, 827-836. [CrossRef]

69. Barba, F.J.; Cortés, C.; Esteve, M.J.; Frígola, A. Study of antioxidant capacity and quality parameters in an orange juice-milk beverage after high-pressure processing treatment. Food Bioprocess Technol. 2012, 5, 2222-2232. [CrossRef]

70. Bull, M.K.; Zerdin, K.; Howe, E.; Goicoechea, D.; Paramanandhan, P.; Stockman, R. The effect of high pressure processing on the microbial, physical and chemical properties of Valencia and Navel orange juice. Innov. Food Sci. Emerg. Technol. 2004, 5, 135-149. [CrossRef] 
71. Zulueta, A.; Esteve, M.J.; Frígola, A. Ascorbic acid in orange juice-milk beverage treated by high intensity pulsed electric fields and its stability during storage. Innov. Food Sci. Emerg. Technol. 2010, 11, 84-90. [CrossRef]

72. Carbonell-Capella, J.M.; Buniowska, M.; Barba, F.J.; Grimi, N.; Vorobiev, E.; Esteve, M.J.; Frígola, A. Changes of antioxidant compounds in a fruit juice-Stevia rebaudiana blend processed by pulsed electric technologies and ultrasound. Food Bioprocess Technol. 2016. [CrossRef]

73. Barba, F.J.; Esteve, M.J.; Frígola, A. High pressure treatment effect on physicochemical and nutritional properties of fluid foods during storage: A review. Compr. Rev. Food Sci. Food Saf. 2012, 11, 307-322. [CrossRef]

74. Barba, F.J.; Esteve, M.J.; Frigola, A. Impact of high-pressure processing on vitamin e ( $\alpha$-, $\delta$, and $\gamma$-tocopherol), vitamin D (cholecalciferol and ergocalciferol), and fatty acid profiles in liquid foods. J. Agric. Food Chem. 2012, 60, 3763-3768. [CrossRef] [PubMed]

75. Craft, B.D.; Kerrihard, A.L.; Amarowicz, R.; Pegg, R.B. Phenol-based antioxidants and the in vitro methods used for their assessment. Compr. Rev. Food Sci. Food Saf. 2012, 11, 148-173. [CrossRef]

76. Keenan, D.F.; Brunton, N.P.; Gromlay, T.R.; Butler, F.; Tiwari, B.K.; Patras, A. Effect of thermal and high hydrostatic pressure processing on antioxidant activity and colour of fruit smoothies. Innov. Food Sci. Emerg. Technol. 2010, 11, 551-556. [CrossRef]

77. Pétrier, C.; Combet, E.; Mason, T.J. Oxygen-induced concurrent ultrasonic degradation of volatile and non-volatile aromatic compounds. Ultrason. Sonochem. 2007, 14, 117-121. [CrossRef] [PubMed]

78. Bitton, G.; Hornero-Méndez, D. Carotenoids and colour in fruit and vegetables. In F.A. Phytochemistry of Fruit and Vegetables, Tomás-Barberan; Robins, R.J., Ed.; Oxford Science Publications: New York, NY, USA, 2001; pp. 11-29.

79. Giovannucci, E. Tomatoes, tomato-based products, lycopene and cancer: A review of the epidemiological literature. J. Natl. Cancer Inst. 1999, 91, 317-331. [CrossRef] [PubMed]

80. Kritchevsky, S.B. $\beta$-Carotene, carotenoids and the prevention of coronary hearth diseases. J. Nutr. 1999, 129, 5-8. [PubMed]

81. Butz, P.; Keller, W.D.; Tauscher, B.; Wolf, S. Ultra-high pressure processing of onions: Chemical and sensory changes. LWT Food Sci. Technol. 1994, 27, 463-467. [CrossRef]

82. Roohinejad, S.; Everett, D.W.; Oey, I. Effect of pulsed electric field processing on carotenoid extractability of carrot purée. Int. J. Food Sci. Technol. 2014, 49, 2120-2127. [CrossRef]

83. Morales-de la Peña, M.; Salvia-Trujillo, L.; Rojas-Graü, M.A.; Martín-Belloso, O. Changes on phenolic and carotenoid composition of high intensity pulsed electric field and thermally treated fruit juice-soymilk beverages during refrigerated storage. Food Chem. 2011, 129, 982-990. [CrossRef] [PubMed]

(C) 2016 by the authors; licensee MDPI, Basel, Switzerland. This article is an open access article distributed under the terms and conditions of the Creative Commons Attribution (CC-BY) license (http://creativecommons.org/licenses/by/4.0/). 